MUZIKOLOŠKI ZBORNIK - MUSICOLOGICAL ANNUAL IV, LJUBLJANA 1968

\title{
K VPRAŠANJU O KOMPOZICIJSKIH NAZORIH SLAVKA OSTERCA
}

\author{
Katarina B edin a (Ljubljana)
}

Slavko Osterc je s svojimi radikalnimi nazori odločilno posegel v razmere slovenskega glasbenega življenja med obema vojnama. Živahno praško glasbeno življenje, ki je v predvojnem času nenehno iskalo stik $\mathrm{z}$ novimi gibanji $\mathrm{v}$ umetnosti, je bistveno vplivalo tudi na dokončno oblikovanje Osterčevega umetniškega prepričanja. Po komaj dveh letih tamkajšnjega študija je bila njegova sodobna umetniška orientacija določena in nazori, ki so se oblikovali hkrati z njo, v glavnem izdelani. V središče slovenskega glasbenega življenja je stopil kot revolucionar, pristaš modernih smeri in vodilna osebnost $\mathrm{v}$ boju za prodor sodobnih kompozicijskih načel pri nas. Za dosego tega cilja je delal vse življenje, kar se odraža v njegovem umetniškem in publicistično-kritičnem delu.

Kot umetniku je bila Ostercu prva in najvažnejša naloga komponiranje, v pisani besedi pa je našel sredstvo za hitrejšo zmago smeri, za katero se je boril ter za pravilno razumevanje lastnega skladateljskega ustvarjanja. Vse Osterčeve izpovedi o umetnostnih in posebej o kompozicijskih nazorih izhajajo zato iz istih vzrokov: dokazati upravičenost in nujnost svoje napredne skladateljske usmerjenosti, doseči afirmacijo sodobnih del pri širšem občinstvu ter odstraniti vse tiste elemente $\mathrm{v}$ slovenskih glasbenih razmerah, $\mathrm{ki}$ so zavirali pot $\mathrm{k}$ sodobnemu umetniškemu izražanju.

Osterc kot pristaš absolutne muzike, zagovornik ațematičnega in atonalnega sloga, ki je iskal nov in lastni glasbeni izraz, je s svojo umetnostjo kmalu naletel na odpor $\mathrm{v}$ javnosti in na negativne ocene $\mathrm{v}$ pretežnem delu kritik v strankarsko opredeljenih glasilih. Preskromna razgledanost pa tudi manjša ustvarjalna moč večine sodobnih, močno na tradicijo vezanih skladateljev pri nas je povzročila večkratne hude idejne borbe. Ostercu so očitali pomanjkanje invencije in čustva, hladni konstruktivizem, originalnost za vsako ceno, cinično zanikanje vseh utrjenih pravil, celo razdirajoče revolucionarni slog. Temu so botrovali poleg provincionalnih glasbenih razmer tudi nesodobni nazori večine tedanjih kritikov, ki so se izključno opirali na pravilnost in globoko razumevanje že priznanih glasbenih vrednot. 'Navadno so temu pridružili še nasvete, kako naj piše mlada skladateljska generacija: le-ta naj bi sledila večnim kvalitetam velikih vzorov iz preteklih dob in uporabljala samo preizkušena kompozicijska sredstva. Vendar je bil Slavko Osterc v sebi dovolj trden, 
pa čeprav na začetku svojega delovanja na domačih tleh domala osamljen, da ni nikdar odstopil od svojih naziranj, temveč je vedno znova pojasnjeval in samozavestno utrjeval svoj odnos in mnenje do novih poti v glasbi.

Problem čustva in razuma je bil največkrat predmet razprave, pri čemer je Osterc jasno opredelil pojem čustva $\mathrm{v}$ umetnosti za razliko od sentimentalnosti. ${ }^{1}$ Osterc je bil prepričan, da se $\mathrm{v}$ absolutni muziki ne dá določiti točne meje med čustvom in razumom: )To vprašanje (odnosa med obojim) se rešuje pri vsaki umetnini sami. Gotovo ima vsaka umetniška glasbena tvorba svoje intelektualno ozadje. $\mathrm{V}$ eni dobi dominira ta struja, v drugi ona, kakršna je pač snov in naloga, ki si jo umetnik zastavi. $\left(^{2}\right.$ Vendar se čustva $\mathrm{v}$ absolutni glasbi ne morejo opisati z besedami; Slavko Osterc zagovarja načelo, da lahko absolutna glasba »... vzbuja prijetna občutja sama na sebi, kot čista umetnost, ki mu (poslušalcu) zavoljo svoje visoke estetske vrednosti zadostuje, da jo lahko in rad sprejema, pa ni treba, da bi pri tem mislil ... na kaj drugega. ( $^{3}$

Tako gleda Osterc z aspekta poslušalca, kot skladatelj pa daje v svojih člankih izključno prednost razumu pred invencijo in čustvom: »Intelekt postavljamo na prvo mesto, ker čuvstvo najdemo pri vsaki živali, a intelekt kakšnemu teletu vsekakor ne moremo priznati. Zahtevamo intelekt pri komponistih! ${ }^{4}{ }^{4}$ Tako naziranje bi bilo enostransko in je popolnoma $\mathrm{v}$ skladu $z$ Osterčevim ciničnim in pogosto nekontroliranim načinom pisanja, toda o tem je tudi natančneje spregovoril: „Skladatelji, ki so se naslonili na gregorianski koral (Palestrina, Lasso, Gallus idr. v 16. stoletju) so zelo pazili na mojstrsko izvedene glasove v polifonem slogu - razum! - gotovo pa so dodali razumski plati mnogo čuvstva, ki ga pa ne moremo ločiti točno po tekstih in razpoloženjih — ta čuvstva lahko smatramo kot splošna religiozna čuvstva ali pa kot $\mathrm{razu} \mathrm{m} \mathrm{sko} \mathrm{z} \mathrm{mož-}$ $\mathrm{n}$ o s t , da so se umeli v besedilo vživeti. $\left(^{5}\right.$ Kadar govori Osterc o čustvu skladbe, mu gre za absolutno vsebino dela, ki se na zunaj ne da ponazoriti niti ostro razdvojiti od razuma, se pravi od kompozicijske tehnike. ${ }^{6}$

1 Pod naslovom »Spor za našo sodobno glasbo« je Osterc odgovoril kritikom na večkratne javne napade; odnos med vsebino in tehniko neke skladbe je takole pojasnil: "Pravijo tudi, da nimam duše. Gospoda, pa še kakšno! Človek, ki se je na primer v svoji oceni o moji Ouverturi norčeval iz mene, mi ne bo govoril o duši. O zadevi duše (invencije) brez pridržka to podpišem, kar je Lajovic objavil lani v Jutru: ,Pogoj umetnine je vsebina’. Seveda je oblika (tehnika) drugi pogoj: če tehnike ne obvladaš, umetnine ne boš mogel narediti.« J XVII/1936, št. 25.

2 »Čuvstvo in razum v glasbi«, Žena in dom VI/1935, št. 4, str. 95.

${ }^{3} \mathrm{Iz}$ rokopisnega zapiska Osterčevega predavanja o skladateljskem delu Rista Savina v Radiu Ljubljana (13. aprila 1937), gl. Osterčevo zapuščino, rkp. odd. NUK.

${ }^{4}$ Zvuk II/1932, str. 104.

5 »Čustvo in razum $v$ glasbi«, Žena in dom VI/1935, št. 3, str. 94.

6 》Gregorianski koral je bil ali accentus ali concentus. Accentus je deklamatoričen način petja, kjer se melodija suče okoli gotovega centralnega tona nekateri toni pa se dvigajo ali padajo za kak majhen interval. Neglede na to, kakšna je vsebina besedila, ali je tukaj v ospredju razum ali čustvo? Če bi bil razum, bi se moralle zapeti važnejše besede močneje, eventuelno višje - če pa čuvstvo, pa bi moral ta način petja biti glede na svetopisemske besede na mestih naravnost ganljiv. In vendar je to petje ... kar najbolj monotono. Vsekakor sili v ospredje razumska plat: vztrajanje na istem tonu, dviganje in padanje na gotovih 
Končno Osterc pravilno ugotavlja, da je umetnini poleg intelekta, to je po njegovem izvirne oblike in tehnike, prvi pogoj tudi skladateljeva ustvarjalna moč, invencija. Za Osterčev lik umetnika in za njegovo umetniško orientacijo sta značilni naslednji misli: »Originalnost smatram za absolutni predpogoj vsake pomembnejše umetnine. ${ }^{7}$ In: »Pri Bachu je nagnjenje $\mathrm{k}$ razumski plati na škodo čuvstvene vidno. Blesteča kontrapunktika je dokaz ogromnega znanja in logike. Da so njegova dela še danes tako sveža kot prej, je močan dokaz Bachove stvariteljske sile, ki si je brez čuvstva tudi ne moremo misliti. $\left(^{8}\right.$

S takimi nazori je bil Slavko Osterc, razumljivo, nasprotnik programske glasbe in tonskega slikanja. ${ }^{9}$ Ob vsaki priložnosti, predvsem pa v presoji sodobnih skladb je poudarjal preživelost strogega dur-molovega sistema, orkestralnih slikanj in barv, wagnerjanske dramatike, senzibilnosti in dramatičnih tremolov ter poděrtoval privrženost novim harmonskim postopom, groteski, karikiranju, lapidarnosti, askezi čustev in kontrastom, posebno $\mathrm{v}$ daljših delih, ${ }^{10}$ kajti $) .$. hvala bogu, smo že iz dobe romantike in dolgovezja (.${ }^{11}$ Hkrati so pomenili ti osnovni Osterčevi nazori o sodobnem načinu izražanja tudi temeljna vodila, ki jih je iskal v glasbi. Danes vemo, da mu jih je razvoj glasbene umetnosti docela potrdil.

Podobno kot je dajal Osterc razumu prednost pred čustvom, se je jasno zavedal pomembnosti glasbene forme. Pri odkrivanju novega izraza je potrebna tudi nova forma, ki bo odgovarjala sodobnemu glasbenemu jeziku. V lastnem skladateljskem delu ji je posvečal veliko skrb ${ }^{12}$ in se ni mogel strinjati z mnenjem nekaterih, da glasbena forma sploh ni potrebna: »Matija Bravničar formo negira, ker jo smatra za nekaj zastarelega, izživljenega. To lahko govori kot samouk. Resnica pa je, da ima vsaka skladba svojo formo, pa če jo je komponist hotel ali ne. Saj je tudi impromtu in improvizacija forma. Seveda pa te zame niso ideal forme, temveč forme nižjega tipa. ( ${ }^{13} \mathrm{Za}$ odkrivanje nove glasbene forme je najbolj ustrezno delo za ansambel z majhno zasedbo; od tod izhaja skladateljeva teza »Živimo v dobi komorne glasbe ... najbrž zaradi tega, ker se je

mestih in približno enaka ritmična vrednost vseh zlogov. Da je pri tem čuvstvo, ni dvoma - drugače bi teksti ne bili peti, ampak govorjeni. Ne moremo pa najti ne logike med tekstom in to melodijo, pa tudi ne nobene čuvstvene zveze med obema.« Concentusu pripisuje zaradi melizmov - kljub isti snovi - prevladovanje čustva, toda s pripombo, da so to »kolektivna čustva«, ki jih »nahajamo tudi $v$ mnogih pozneje nastalih skladbah, npr. narodnih pesmih«. Ibid.

7 Jutro XVII/1936, št. 26.

8 »Čuvstvo in razum $v$ glasbi«, Žena in dom VI/1935, št. 3, str. 94.

9 Osterčev komentar h koncertu UJME (16. decembra 1940), rkp. odd. NUK.

$10 \mathrm{~V}$ skriptah »Glasbena zgodovina« je Osterc označil osnovne tendence v skladbah Igorja Stravinskega, ki jim je tudi sam sledil v lastnem ustvarjanju: »... namesto sentimanta sarkazem, namesto romantike humor, razvijanje melodije okrog enega, dveh, treh tonov, barbarski ritmi, namesto komponiranja zaljubljenih pesmi, šaljivke.《

11 Ljubljanski zvon XVIII/1928, št. 6.

12 » Jaz sem [v Klavirskem triu iz leta 1929] spet reševal problem forme, kjer naj se nič ne ponavlja.« Radio Ljubljana XII/1940, št. 40, str. 5.

13 Ljubljanski zvon L/1930, št. 6, str. 378. 
forma sočasnih komornih del že precej ustalila in dobiva vedno bolj konkreten izraz. Nekoliko počasneje pa gre to s simfonično glasbo. ${ }^{14}$

$\mathrm{V}$ iskanjih sodobne glasbene forme je našel Osterc tudi vzrok za upadanje produkcije modernih oper: „Kakor $\mathrm{v}$ Bachovih časih, tako tudi danes prevladuje takozvana formalistična struja nad izrazno, onostransko. ... Verjetno je, da je ta princip poslednjih dveh decenijev vplival negativno na razvoj opere, pri kateri je glasba neizogibno vezana $z$ dano vsebino ter tudi bolj ali manj od nje odvisna. Že $v$ pesmicah mora skladatelj upoštevati ritem ter koliko toliko izraz besedila. Čim večja je pa oblika, tem bolj prehaja skladateljska funkcija pri obdelavi pesniških snovi v sekundarnost. ${ }^{15}$ Kot reakcija na nasičeno ilustrativno in programsko glasbo romantike so začela sodobna skladateljska prizadevanja nagibati k absolutni glasbi, »absolutna glasba brez forme pa je nemogoča in ni čuda, da so se začele spet pisati opere z zaključenimi točkami. $\left({ }^{16}\right.$ Zaključene točke v operi (recitativi, arije, zbori idr.) dajejo več možnosti za oblikovanje form nasproti veliki razsežnosti Wagnerjeve glasbene drame, ki je vezana na vsebino in izraz teksta. Izrazito dramatični teksti zahtevajo programsko glasbo in glede tega je Osterc $\mathrm{v}$ presoji Wagnerjevih oper pravičen: „Prednosti wagnerskega principa so $\mathrm{v}$ glavnem: čim večja podobnost govorjeni drami, pravilna dolžina prizorov, velika enotnost $v$ arhitekturi in čim intenzivnejše sorodstvo med besedo in glasbo. Glasba dobi $\mathrm{s}$ tem značaj podrejenosti in velike resničnosti, mogoče tudi velikega doživetja. In dramatična je ta glasba nedvoumno. Slabe lastnosti so naštete že v prejšnjem stavku, največja pa je ta, da lahko postane monotona. (c ${ }^{17}$

Čeprav je bil Osterc pristaš novih iskanj, se ni navduševal nad vsem novim že zaradi novosti samih. Kakor pri ocenjevanju starejših del, tako je hotel biti tudi pri sodobnih čim bolj objektiven, pri čemer je vedno uporabljal konkretne primere in jih dokazoval. Za primer sodobne opere si je vzel Hindemithovo opero Cardillac in poizkusil pojasniti, zakaj ni izzvala večjega uspeha. Vzrok je našel ponovno $\mathrm{v}$ dejstvu, da konkretna vsebina s sodobno abstraktno glasbo ne more predstavljati homogene celote: „Preveč glasbe za premalo dejanja; čiste, absolutne glasbe, ne teatrske. Glasbo bi najlažje primerjal z Bachovo. ... Hindemith daje prednost formi (niso pa to recitativi, arije, dueti, ampak se vrstijo fuge, pas-

14 GLOLj (Gledališki list, Opera, Ljubljana) 1927/28 št. 17, str. 205 - Osterc je z zadovoljstvom opažal, da so ustvarjalne sile nekaterih slovenskih sodobnikov in njegovih učencev $\mathbf{v}$ tej smeri dosegle že vidne uspehe doma in $\mathbf{v}$ tujini: $\gg \mathrm{Na}$ pobudo Zikovega kvarteta ... so pri nas komponisti začeli posvečati komorni glasbi več pažnje. Kar preko noči smo »vdrli« v Zagreb, Beograd, Dunaj, Prago, Brno, Varšavo, Moskvo, Firenco, Pariz, London, Ženevo itd. In to z uspehom, ki ga ni nihče pričakoval. Vse kritike so nam priznale »življenjski prostor «... S komorno glasbo smo si Slovenci pravzaprav priborili dostojno mesto $v$ mednarodnem glasbenem svetu. ... Razumljivo je, da so se tej panogi posvetili skoráj vsi seriozni slovenski komponisti. Prav tako je razveseljivo, da imamo v Ljubljani že troje tovrstnih udruženj: Ljubljanski godalni kvartet, Radijski godalni kvartet in Radijski klavirski trio«. »Slovenska komorna glasba«, Radio Ljubljana XII/1940, št. 49, str. 5 .

15 GLOLj 1927/28, št. 17, str. 206.

16 Ljubljanski zvon XLIX/1929, št. 6, str. 380.

17 Ibid., str. 381. 
sacaglie, cannoni, da, celo sonate). Mogoče pretirava, ter s tem izgublja dramski učinek.(18

Nekateri sodobniki so bili mnenja, da Wagner-Regenyjeva opera Kraljičin ljubimec, ki se naslanja na Haendlov in Mozartov vzor, predstavlja izhod iz sedanje krize. Osterc $\mathrm{v}$ publicističnem delu ni nakazal smernic, kako naj bi se rešil problem sodobne opere, toda $\mathbf{v}$ Wagner-Regenyjevem delu je videl »skrajno neuspel poizkus eksploatiranja starega, dobrega blaga.( ${ }^{19}$ Kljub temu da ni prišel do končnih predstav o bodočem razvoju operne glasbe, ${ }^{20}$ je Osterc videl eno izmed rešitev, ki bi se ujemala s sodobnim muzikalnim izrazom, $v$ libretih abstraktne vsebine, komponiranih za komorne ansamble $\mathrm{v}$ smislu glasbenega skeča, ker »na dramske tekste je glasba lahko ilustrativna, na abstraktne pa čista, absolutna. ( ${ }^{21}$ Toda: )Vsi iščejo. Vse kaže, da še niso našli ter $\mathrm{v}$ bližnji bodočnosti ne bodo, kajti današnja doba ni operna. $\left({ }^{22}\right.$

Razvoj na opernem področju do danes tudi še ni prinesel ustreznega odgovora, zato nimamo stvarne podlage, da bi katero navedenih Osterčevih prepričanj in ugibanj dopolnili, lahko se pa pridružimo njegovim ugotovitvam vsaj glede izbire abstraktnih, arhaističnih, komičnih in lapidarnih tekstov brez zunanje tragike ter glede komornega sestava izvajalcev.

Osterčevi kompozicijski nazori so najbolj jasni v kritikah del slovenskih in jugoslovanskih ustvarjalcev, kjer se je počutil kot voditelj-ocenjevalec še posebno odgovornega. Prizadeval si je, da bi mlade skladatelje pritegnil $\mathrm{v}$ vrsto domačih avantgardistov, $\mathrm{ki}$ bi čimprej dosegla raven evropskega razvoja ter se mu enakovredno pridružila. Spodbujal je tiste, ki so začeli segati po sodobnem glasbenem jeziku in tiste, ki se za moderna kompozicijska sredstva še niso mogli odločiti. Nekatere je pridobil z uspehi lastnih del $\mathrm{v}$ tujini in kot pedagog, istim načelom pa je $\mathrm{v}$ veliki meri utiral pot tudi $\mathrm{v}$ publicistiki. Zagovarjal jih je prepričljivo in $\mathrm{z}$ zaupanjem v njihovo pravilnost. Značilne so Osterčeve besede: »Če favoriziram predvsem one domače skladbe, ki so hipermoderne, ima to seveda svoje vzroke. ... [ [ n njih] sem našel originalnost, medtem ko skladbe starejših smeri vedno spominjajo na kakega Wagnerja, Debussyja in Brahmsa. ... Zakaj pišem tako in drugače? Ker je čedalje več povpraševanja po mojih skladbah iz vsega sveta. ${ }^{23}$ Zahteva po originalnosti in uporabi sodobnih kompozicijskih sredstev je služila Ostercu za sredstvo, ki mora domače glasbeno ustvarjanje izviti iz njenega provincialnega značaja, ki je bil še tako daleč za stopnjo razvoja naprednih gibánj v svetu. Osterc se je zavedal, da bo mogla le široka uveljavitev sodobne glasbene govorice ustvariti ugodna tla delovanju naših ustvarjaĪnih moči.

18 GLOLj 1927/28, št. 17, str. 206.

19 »Spor za našo sodobn glasbo« I, J XVII/1936, št. 25.

20 »Vočka [Wozzeka], Cardillaca in Jonnyja sicer smatram kot tri poiskuse, ki naj bi dali operi novo smer. Vendar sem mnenja, da si kljub visoki kvaliteti ne bo noben po izvirnosti stremeč komponist vzel te ali one za vzor.« GLOLj 1927/28, št. 17 , str. 205 .

21 Zbori V/1929, št. 5, str. 25.

22 GLOLj 1927/28, št. 17, str. 205.

23 »Spor za našo sodobno glasbo« I in II, Jutro XVII/1936, št. 25. 


\section{SUMMARY}

Slavko Osterc entered into the centre of Slovene musical life as a revolutionary, as a champion of modern, world art trends and as the leading personality in the struggle for the introduction of contemporary principles of composition into the music of our contry. He devoted all his endeavours in art and in the field of criticism to this end. He found in the written word a more immediate means for affirming contemporary works of composition before a wide audience, and for removing those elements in Slovene musical life which impeded this affirmation. As a follower of absolute music, athematic and atonal style, he soon came up against resistance and negative appreciation from the critics who published their reviews in the various papers, representing different political standpoints. They reproached him for lack of invention and feeling, cold constructivism, his striving for originality at any cost, for his destructive revolutionary style and so on. These attacks, however could not weaken Osterc's addiction to contemporary music, but instead he ever consolidated his attachment to new paths in music: in composition he gave preference to intellect and not to emotion, to form and not to content; in his judgements he emphasized that the strict major-minor system was out-of-date, as were orchestral painting, Wagnerian dramatics, sensibility and dramatic tremoloes; and so he stressed his affinity to new and bold harmonic progressions, to grotesque, to caricature, starkness, asceticism of emotion and to contrapunctal treatment especially in his longer works. Being convinced that for new content we must also find new musical forms, corresponding to contemporary idiom, he thought that an original solution of the formal problem is the first condition for every important composition. In his opinion, old proven traditional forms, whether in chamber, symphonic or operatic music, are incompatible with the expression of a new content. In this fact Osterc also saw the main reason, on the one hand, for the rather small contemporary output of symphonic and operatic works, and, on the other hand, for the varied chamber work production, because its small setting is most appropriate for the search for new possibilities in form and content. Thus in his creative work he devoted special care to chamber music. At the same time he stimulated those who were just beginning to employ contemporary composition techniques to discover further new ways, and encouraged those who had not yet decided on modernism to attempt such new techniques. He endeavoured to attract young composers to the ranks of our avantgarde so that they might attain the level of European development and then take an equal part in it. 